\title{
VIEWPOINT
}

\section{Heart rate variability: why do spectral analysis?}

\author{
John M Karemaker
}

Measurement of heart rate variability (HRV) by spectral analysis has become a hot issue in cardiology in recent years. Originally this technique was promoted by well-known clinicians and physiologists who reported that HRVgave insights into sympatho-vagal balance in autonomic outflow. ${ }^{1-3}$ This led to it being applied to the assessment of mental ${ }^{4}$ or physical stress ${ }^{5}$ on the one hand and the diagnosis of autonomic neuropathy ${ }^{6}$ on the other. Later it became apparent that HRV analysis might help in risk assessment of patients, for instance after myocardial infarction. ${ }^{7}$ It was found that decreased HRV points to a poor prognosis, probably related to the decreased cardioprotective activity of the parasympathetic system. Despite difficulties with the interpretation and in application of the techniques, ${ }^{8}$ many are using HRV analysis in clinical research.

Heart rate variability is mainly a reflection of the influence of the autonomic nervous system on the sinus node of the heart. The heart rate alters with many of the changes in demand on the cardiovascular system that are related to changes in respiration, posture, and physical or mental activity. These changes are invoked by the control mechanisms that coordinate the total pattern of activity in the individual. We need information on this total activity to interpret HRV correctly. For instance, unless we were aware of the highly emotional conversation that took place, a sudden increase in blood pressure and heart rate in someone apparently sitting quietly at his desk would be incomprehensible.

Data on blood pressure changes are essential for the understanding of short-term HRV because much of it is under baroreflex control. ${ }^{9}$ In the blood pressure to heart rate reflex loop the vagus nerve induces fast, brisk changes in the activity of the sinus node. ${ }^{10}$

\section{Glossary}

HRV = Heart rate variability-continual change in heart rate even under stable conditions

$\mathrm{HF}=$ High frequency-the variations in heart rate at a rate from about one oscillation per six seconds and faster. HF variations are mostly coupled to respiration

$\mathrm{LF}=$ Low frequency-variations in heart rate at slower rhythms than HF. Prominent LF oscillations at a rate of about one per 10 seconds are seen, but slower rhythms are also seen
This to a large extent explains why a decrease in vagal outflow as observed after myocardial infarction induces lower HRV and lower baroreflex sensitivity scores. ${ }^{711}$

\section{Use of HRV measurement}

Measurement of HRV and heart rate changes in response to known stressors is used for various purposes. The technique should be adapted to the aim of the investigation.

In the diagnosis of cardiovascular autonomic neuropathy a combination of three classic tests-blood pressure and heart rate responses to deep breathing, standing up, and Valsalva's manoeuvre-gives a quick and clinically useful indication of the site and extent of impairment. There are age-related limits of normal responses for these tests. ${ }^{12}$ The Finapres technique for the measurement of continuous blood pressure has helped to improve the diagnostic power of these tests. ${ }^{13}$ In recent years spectral analysis of HRV in the supine and standing position has been proposed for the diagnosis of diabetic autonomic neuropathy. ${ }^{14}{ }^{15}$ However, the wide variance in the results of these HRV tests and the required lengths of stationary ECG data sets has limited use of these newer techniques.

HRV analysis in risk assessment-for example, in patients after myocardial infarctionrequires techniques and data sets other than the relatively short-lasting records (5 to 10 minute recordings) that are required for investigation of momentary autonomic state. Here the availability of $24 \mathrm{~h}$ Holter recordings seems to have opened a new era in biomathematics. ${ }^{16} 17$ The very low frequency variability at frequencies below those that are generally considered the result of properties of the baroreflex control loop seems to be an especially good indicator of general health. ${ }^{18} \mathrm{But}$ analysis techniques other than Fourier analysis of harmonic content or more classic statistical approaches are also being considered. These include Poincaré plots, ${ }^{19}$ fractal dimension, ${ }^{20}$ or apparent entropy. ${ }^{21}$ These techniques take a more global look at HRV than those that interpret HRV in terms of sympathetic and parasympathetic (baroreflex) control of the cardiovascular system. The HRV signal is considered more or less as a chaotic signal with hidden features. Because of the long data 
stretches that are required for these analyses few researchers have applied them to recordings of heart rate with continuous blood pressure. The technique for $24 \mathrm{~h}$ continuous blood pressure has been limited to a few centres which use portable intra-arterial recording techniques. Presently the portable version of Finapres (Portapres) intended for $24 \mathrm{~h}$ use is gradually coming out of the laboratory. ${ }^{22}$

Guidelines in HRV: the task force's report Recently a task force of the European Society of Cardiology and the North American Society of Pacing and Electrophysiology has delivered its report on proposed standards of measurement, physiological interpretation, and clinical use for heart rate variability. ${ }^{23}$ This group of experts in mathematics, engineering, physiology, and clinical medicine has reviewed a wide area of techniques and applications for this new tool in cardiology. The emphasis in the report is very much on measurement and computational techniques. The physiological mechanisms underlying HRV are only touched on. This may give the impression that much of the physiology in HRV is settled and that we only have to consider the choice of the right computational technique for a specific study.

\section{Critique}

The origin and meaning of HRV are much debated in various circles of researchers. Some have tried to fit the experimental observations to simple physiological models. ${ }^{924}$ The task force report adopts a more global view, emphasising the distinction between low frequency (LF) and high frequency (HF) HRV and viewing $L F$ as sympathetic and $H F$ as parasympathetic cardiovascular control. This is an oversimplification and detracts from the unsolved fundamental problems in HRV analysis. Basic physiology indicates that shortterm HRV is to a large extent baroreflex-mediated. Various techniques have been proposed to extract measures for baroreflex sensitivity (BRS) from the combined spontaneous fluctuations in beat-to-beat blood pressure and heart rate. ${ }^{25} 26$ Some members of the task force applied these measures themselves ${ }^{27}$ or stressed the importance of BRS measurement to risk assessment in patients after myocardial infarction. ${ }^{1128-30}$ From this perspective the task force's report seems to have overemphasised computation, possibly to avoid being too opinionated.

In 1995 Sleight et al asked "Is power spectral analysis largely an index of baroreflex gain?". ${ }^{31}$ They showed that the model of DeBoer et $\mathrm{al}^{9}$ was probably correct in explaining $\mathrm{LF}(0 \cdot 1 \mathrm{~Hz})$ blood pressure variations as a resonance phenomenon in the blood pressure response to peripheral resistance baroreflex. In this model HRV is a consequence of the baroreflex modulation of the sinus node by cardiac parasympathetic and sympathetic activity. This relates HF and LF HRV to heart rate control by the vagus nerve (HF) and com- bined vagus and sympathetic activity (LF). The existence of LF oscillations in blood pressure is explained as a result of sympathetic vasomotor activation probably originating in the baroreflex to sympathetic feedback loop. This model does not preclude other mechanisms inducing oscillations in blood pressure in the LF band; however, under normal conditions the feedback mechanism of the baroreflex is sufficient to explain the experimental observations. In addition, it explains why parasympathetic blockade by atropine not only abolishes HF HRV but also strongly reduces LF HRV.

For testing the autonomic state by spectral analysis short-term stable recordings of continuous blood pressure and heart rate can be sufficient; short-term, as proposed in the task force report, being at least five minutes. Moreover, the cardiovascular control system must be challenged to show its regulatory capacity. Therefore one recording only in the supine position will, on most occasions, be insufficient. When they are supine most people need little contribution from the sympathetic nervous system to cardiovascular control. Orthostatic stress will unveil a shift from the mainly parasympathetic supine state to a sympathetically dominated upright position. ${ }^{32} 33$

However, in many cases of cardiovascular disease the required recordings are very hard to obtain. Frequent cardiac arrhythmias can make it impossible to obtain a clean recording of sufficient data length to do any spectral analysis. Moreover, the classic tests mentioned above (deep breathing, Valsalva's manoeuvre and, if conditions allow, a standing test) will give most of the required data on the condition of autonomic cardiovascular control. If the sensitivity of the baroreflex needs to be assessed, the classic phenylephrine test can be used to demonstrate its capacity to influence heart rate (expressed as ms interval prolongation per $\mathrm{mm} \mathrm{Hg}$ increase of systolic blood pressure). Intra-arterial recording can be replaced by Finapres. ${ }^{34}$

Limited and cautious interpretation of HRV spectra is required. For diagnostic use in the autonomic function laboratory spontaneous HRV as measured in conventional Holter recordings should be combined with responses to classic manoeuvres. Among these are the blood pressure and heart rate responses to standing, Valsalva's manoeuvre, and the deep breathing test. We must avoid making unwarranted claims for clinical tests, as were made for Vmax some years ago where modelling and computing seemed to receive more attention than clinical sense and sound physiology.

1 Pagani M, Lombardi F, Guzzetti S, Sandrone G, Rimoldi Pagani M, Lombardi F, Guzzetti S, Sandrone G, Rimoldi
O, Malfatto G, et al. Power spectral density of heart rate variability as an index of sympatho-vagal interaction in subjects. F Hypertens 1984; 2(suppl):S383-S385.

2 Lombardi F, Sandrone G, Pernpruner S, Sala R, Garimoldi $M$, Cerutti $S$, et al. Heart rate variability as an index of sympathovagal interaction after acute myocardial infarction. Am f Cardiol 1987;60:1239-45.

3 Saul JP, Arai Y, Berger RD, Lilly LS, Colucci WS, Cohen 
RJ. Assessment of autonomic regulation in chronic congestive heart failure by heart rate spectral analysis. $\mathrm{Am} \mathcal{F}$ Cardiol 1988;61:1292-9.

4 Langewitz W, Ruddel H. Spectral analysis of heart rate variability under mental stress. F Hypertens 1989;7 (suppl):S32-S33.

5 Pagani M, Somers V, Furlan R, Dell'Orto S, Conway J Baselli $\mathrm{G}$, et al. Changes in autonomic regulation induced by physical training in mild hypertension. Hypertensio 1988;12:600-10.

6 Bernardi L, Ricordi L, Lazzari P, Solda P, Calciati A Ferrari MR, et al. Impaired circadian modulation of sympathovagal activity in diabetes. A possible explanation for altered temporal onset of cardiovascular disease. Circulation 1992;86:1443-52.

7 Kleiger RE, Miller JP, Bigger JT, Jr, Moss AJ. Decreased heart rate variability and its association with increased mortality after acute myocardial infarction. $A m \mathcal{F}$ Cardio 1987;59:256-62

8 Malik M, Camm AJ. Components of heart rate variability - what they really mean

9 DeBoer RW, Ka.mat Strackee J Hemodynamic fluctuations and baroreflex sensitivity in humans: a beatto-beat model. Am $\Im$ Physiol 1987;253:H680-H689.

10 Berger RD, Saul JP, Cohen RJ. Transfer function analysis of autonomic regulation. I. Canine atrial rate response. of autonomic regulation. I. Canine

11 Farrell TG, Odemuyiwa O, Bashir Y, Cripps TR, Malik M, Ward DE, et al. Prognostic value of baroreflex sensitivity testing after acute myocardial infarction. Br Heart $\mathscr{F}$ 1992;67:129-37.

12 Wieling $W$. Non-invasive continuous recording of hear rate and blood pressure in the evaluation of neuro-cardiovascular control. In: Autonomic failure. A textbook of clinical disorders of the autonomic nervous system. Bannister Mathias CJ, eds. Oxford: Oxford University Press 1992: 291-311.

13 van Lieshout J, Wieling W, Wesseling $\mathrm{KH}$, Karemaker JM. Pitfalls in the assessment of cardiovascular reflexes in patients with sympathetic failure but intact vagal control. Clin Sci (Colch) 1989;76:523-8.

14 Lishner M, Akselrod S, Avi VM, Oz O, Divon M, Ravid $M$. Spectral analysis of heart rate fluctuations. A noninvasive, sensitive method for the early diagnosis of auto nomic neuropathy in diabetes mellitus. $\mathcal{f}$ Auton Nerv Syst nomic neuropathy

15 Ziegler D, Laux G, Dannehl K, Spuler M, Muhlen H, Mayer $\mathrm{P}$, et al. Assessment of cardiovascular autonomic function: age-related normal ranges and reproducibility of spectral analysis, vector analysis, and standard tests of heart rate variation and blood pressure responses. Diabe Med 1992;9:166-75.

16 Signorini MG, Cerutti S, Guzzetti S, Parola R. Non-linear dynamics of cardiovascular variability signals. Methods Inf Med 1994;33:81-4.

17 Yamamoto Y, Hughson RL. Coarse-graining spectral analysis: new method for studying heart rate variability. Appl Physiol 1991;71:1143-50.

18 Bigger JT, Jr, Fleiss JL, Steinman RC, Rolnitzky LM Kleiger RE, Rottman JN. Correlations among time and frequency domain measures of heart period variability two weeks after acute myocardial infarction. Am $\mathcal{f}$ Cardiol two weeks after

19 Woo MA, Stevenson WG, Moser DK, Trelease RB,
Harper RM. Patterns of beat-to-beat heart rate variability in advanced heart failure. Am Heart f 1992;123:704-10.

20 Yeragani VK, Srinivasan K, Vempati S, Pohl R, Balon R. Fractal dimension of heart rate time series: an effective measure of autonomic function. $\mathcal{F}$ Appl Physiol 1993;75: 2429-38.

21 Pincus SM, Goldberger AL. Physiological time-series analysis: what does regularity quantify? Am $\mathcal{F}$ Physiol

22 Imholz BP, Langewouters GJ, van Montfrans GA, Parati G, van Goudoever J, Wesseling KH, et al. Feasibility of ambulatory, continuous 24-hour finger arterial pressure recording. Hypertension 1993;21:65-73.

23 Camm AJ, Malik M, Bigger JT, Breithardt G, Cerutti S, Cohen RJ, et al. Heart rate variability-standards of measurement, physiological interpretation, and clinical use. Circulation 1996;93:1043-65.

24 Baselli G, Cerutti S, Livraghi M, Meneghini C, Pagani M Rimoldi $O$. Causal relationship between heart rate and arterial blood pressure variability signals. Med Biol Eng Comput 1988;26:374-8.

25 Robbe HW, Mulder LJ, Ruddel H, Langewitz WA, Veldman JB, Mulder G. Assessment of baroreceptor reflex sensitivity by means of spectral analysis. reflex sensitivity by means

26 Parati G Frattola A, DiRienzo M, Castiglioni P, Pedotti A Mancia G. Effects of aging on 24-h dynamic baroreceptor control of heart rate in ambulant subjects. $A m$ tor control of heart rate in amt

27 Furlan R, Piazza S, Bevilacqua $M$, Turiel M, Norbiato G, Lombardi F, et al. Pure autonomic failure-complex abnormalities in the neural mechanisms regulating the cardiovascular system. $\mathcal{F}$ Auton Nerv Syst 1995;51: 223-35.

28 Farrell TG, Paul V, Cripps TR, Malik M, Bennett ED, Ward D, et al. Baroreflex sensitivity and electrophysiological correlates in patients after acute myocardial infarction. Circulation 1991;83:945-52.

29 De Ferrari GM, Landolina M, Mantica M, Manfredini R, Schwartz PJ, Lotto A. Baroreflex sensitivity, but not heart rate variability, is reduced in patients with life-threatening ventricular arrythmias long after myocardial infarcing ventricular arrhythmias long after

30 tion. Am Heart $1995,130.473-80$. E, Just H, Schwartz PJ. Reflex versus tonic vagal activity as E, Just H, Schwartz PJ. Reflex versus tonic vagal activity as a prognostic parameter in patients with sustained ventricular tachycardia

31 Sleight P, La Rovere MT, Mortara A, Pinna G, Maestri R, Leuzzi S, et al. Physiology and pathophysiology of heart rate and blood pressure variability in humans: is powe spectral analysis largely an index of baroreflex gain (published erratum in Clin Sci (Colch) 1995;88:733. Clin Sci (Colch) 1995;88:103-9.

32 Lipsitz LA, Mietus J, Moody GB, Goldberger AL. Spectral characteristics of heart rate variability before and during postural tilt. Relations to aging and risk of syncope. Circulation 1990;81:1803-10.

33 Piccirillo G, Fimognari FL, Viola E, Marigliano V. Ageadjusted normal confidence intervals for heart rate variability in healthy subjects during head-up tilt. Int $\mathcal{f}$ Cardiol 1995;50:117-24.

34 Imholz BP, Parati G, Mancia G, Wesseling KH. Effects of graded vasoconstriction upon the measurement of finger arterial pressure. $\mathcal{f}$ Hypertens 1992;10:979-84. 